\section{PEER-REVIEWED ARTICLE}

Food Protection Trends, Vol 40, No. 5, p. 332-348 Copyright 2020 , International Association for Food Protection 2900 100th Street, Suite 309, Des Moines, IA 50322-3855
Sarah J. Cope, ${ }^{1}$ Anna C. S. Porto-Fett, ${ }^{2}$ John B. Luchansky, ${ }^{2}$ Jill Hochstein ${ }^{3}$ and Benjamin Chapman ${ }^{1 *}$

${ }^{1}$ Dept. of Agricultural and Human Sciences, North Carolina State University, Raleigh, NC 27695, USA

2U.S. Department of Agriculture, Agricultural Research

Service, Wyndmoor, PA 19038, USA

${ }^{3}$ University of Nebraska-Lincoln, Lincoln, NE 68588, USA

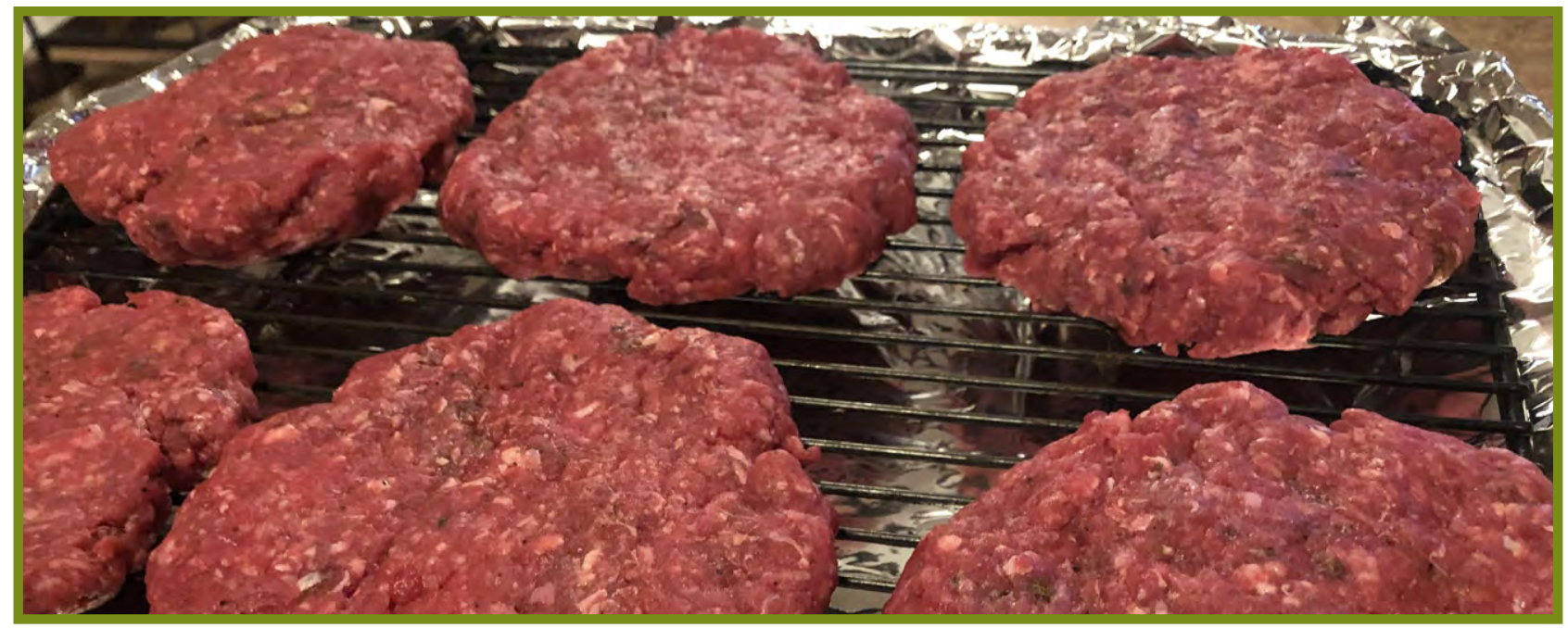

\title{
Utilization of Quantitative and Qualitative Methods to Investigate the Impacts of a Pilot Media Campaign Targeting Safe Cooking Techniques and Proper Thermometer Use
}

\section{ABSTRAGT}

The " $160^{\circ}$ is good" campaign (www.160isgood.com) was launched to inform consumers on proper use of a thermometer to lower the risk of illness from Shiga toxin-producing Escherichia coli (STEC) in beef burgers. A telephone survey administered prior to and after the campaign focused on perceptions of beef food safety, thermometer use, and burger handling practices. Following the campaign, six focus groups (44 total participants) were conducted to measure the effectiveness of the campaign. Of the 305 post-campaign respondents interviewed by phone, ca. $44 \%(n=134)$ recalled hearing a beef safety-related advertisement, whereas ca. $24 \%(n=72)$ reported hearing the " $160^{\circ}$ is Good" message. Additionally, $14 \%(n=44)$ of pre-campaign respondents, compared with $16 \%$ ( $n=50$ ) of postcampaign respondents, used a thermometer to determine "doneness" of burgers. Participants complimented the novelty and effectiveness of an animated movie theater pre-roll delivered to a captive audience, while others expressed skepticism about the effectiveness of a radio spot to attract consumers to a website to learn more about food safety. Nevertheless, the " $160^{\circ}$ is Good" campaign increased overall awareness of beef safety within a targeted geographic region and generated a roadmap for future development and delivery of a science-based and effective food safety message for the masses.

\section{INTRODUCTION}

Shiga toxin-producing Escherichia coli (STEC) remains a serious public health concern in the U.S., being responsible for some 265,000 illnesses each year and causing numerous, often large-volume, product recalls (16, 22, 32, 33). Although tainted water and various contaminated foods, especially fresh produce, have on several occasions caused human illnesses attributed to STEC, undercooked or improperly handled beef is the foremost foodborne vehicle worldwide for infections caused by STEC $(5,8,22,33,37)$. Cells of this pathogen were recovered from raw beef at frequencies of $\leq 1.0$ to ca. $55 \%$, with positive samples typically containing ca. 0.5 to $4.0 \mathrm{log}$ $\mathrm{CFU} / \mathrm{g}(12,28,31)$. Given the presence and levels of STEC associated with raw beef and given that even a handful of 
cells can cause gastrointestinal distress so severe that about one-third of infected individuals will require hospitalization $(32,36,39)$, the most effective way to appreciably lower the risk of illness from STEC is to cook ground/non-intact raw beef to an instantaneous internal temperature of $\geq 160^{\circ} \mathrm{F}$ $\left(71.1^{\circ} \mathrm{C}\right)$ as determined by a food thermometer, and to subsequently avoid post-cooking (cross) contamination of the cooked beef (38).

Much has been published in the scientific literature on thermal inactivation of STEC during cooking of ground beef burgers of various sizes, shapes, densities, etc. and with use of several different cooking techniques, times, temperatures, and appliances (e.g., gas grills, clam shell-type grills, flat surface electric grills, etc.) $(4,13,15,21,26,27)$. Despite minor differences in lethality of STEC related to methodologies and materials, as well as strain-to-strain variations, there is very good agreement among studies that cooking beef burgers to an instantaneous internal temperature of $\geq 160^{\circ} \mathrm{F}\left(71.1^{\circ} \mathrm{C}\right)$ delivered a 5-log reduction in levels of the seven regulated serovars of STEC. This scientifically sound and practically relevant information on cooking parameters, appliances, and thermometers used for delivering the requisite 5-log reduction of STEC in ground beef burgers has been published extensively in peer-reviewed scholarly journals. Such periodicals might be requisite reading for food safety professionals but would not be accessible or of interest to the typical consumer. Since everyone has a role to play in keeping foods safe, more efforts are needed to communicate practically relevant, easy-to-digest, readily adoptable food safety practices to consumers. The tactic implemented herein to lessen the risk of illness from STEC was to develop a mass media campaign (" $160^{\circ}$ is Good") centered around proper cooking temperatures/techniques and the use of a food thermometer to determine doneness of grilled burgers when cooked on a grill.

The " $160^{\circ}$ is Good" campaign was created and conducted with the assistance of a national marketing/advertising agency with the goal of educating consumers about safer food handling and preparation techniques. This campaign included an interactive website, display and video banner advertisements on webpages, radio advertisements, press releases, broadcast interviews, movie theater pre-roll advertisements, and a web-based responsive quiz. Each of these work products contained the various aspects of specific food safety wording regarding thermometer use when grilling beef burgers and the specific " $160^{\circ}$ is Good" logo and slogan. The campaign was delivered over a 16 -week period via radio, movie theater, and digital advertisements in a city of some 210,000 people in the Southeast portion of the U.S. When considering mass media campaign advertising to increase food safety knowledge and to create behavior change, it is important to consider behavior change models and what might influence and resonate with people when they are exposed to messaging advertisements. The genesis, creative aspects, dissemination, and outcomes of this marketing initiative is the subject matter of a companion publication (6), whereas assessing its potential impact via phone calls and focus groups is the sole focus of the present study (7). Our primary objective was to gather insight into consumers' behaviors, perceptions, and attitudes surrounding ground beef burgers in response to a marketing/advertising campaign centered around STEC and proper thermometer use when cooking beef burgers with the goal of appreciably lowering the risk of STEC infection.

\section{MATERIALS AND METHODS \\ The " $160^{\circ}$ is Good" campaign}

With the assistance of one of the Midwest's largest providers of marketing services/products, the Shiga toxinproducing Escherichia coli Coordinated Agriculture Project (STEC CAP) team developed and launched the " $160^{\circ}$ is Good" campaign to directly provide consumers with practically-relevant and easily assimilated knowledge, skills, and abilities related to proper thermometer use for safely cooking beef burgers. The campaign was conducted between Memorial Day and Labor Day of 2017 in the metropolitan area of Fayetteville, NC, population ca. 210,000. Fayetteville was selected from among four comparable metropolitan areas (researched and capsulized by our collaborating national marketing/advertising agency) because it reflected the targeted demographic profile of a medium-sized media market in the United States that would also deliver the greatest return on investment for the available budget (ca. $\$ 200,000.00$ USD). All else being equal among the four qualifying metropolitan areas, greater consideration was also given to Fayetteville over the other three finalist cities because of its close proximity (ca. 65 miles) to one of our collaborating institutions, North Carolina State University (Raleigh, NC). The geographic area of the test market was delineated by zip code, with the proportions of respondents interviewed within each of the six zip codes being relatively consistent both pre- and post-campaign (Table 1). The " $160^{\circ}$ is Good" campaign was comprised of banner advertisements with the campaign logo and slogan (Fig. 1), two 30-sec radio public service announcements (PSA), the same radio audio clips accompanied by the logo and slogan, available on a mobile digital music radio application, and a 30-sec movie theater pre-roll advertisement The campaign also hosted an interactive website that included a web-based responsive quiz and the movie theater pre-roll (www.160isgood.com). Along with the specific " $160^{\circ}$ is Good" logo and slogan, each of the abovementioned elements of the " $160^{\circ}$ is Good" campaign contained the various aspects of specific food safety wording regarding proper thermometer use when grilling beef burgers to an instantaneous internal temperature of $160^{\circ} \mathrm{F}$ (38). Collectively, the work products of the campaign generated a total of $11,502,718$ impressions, with an impression being a single time that campaign materials 


\section{TABLE 1. The "160" is Good" campaign phone survey questionnaire}

\section{Questions}

Are you one of the primary meal preparers in your household?

To ensure that we include all age groups in our sample, please tell me which category includes your age?

Can I please have your zip code?

And for classification purposes only, are you of Hispanic, Latino, or Spanish origin?

Gender

When cooking ground beef hamburger patties, how do you TYPICALLY determine when the burgers are done?

Do you ALWAYS, OFTEN, SOMETIMES, RARELY, or NEVER use the following techniques to determine if hamburger patties are done?

A. Measure the internal temperature with a food thermometer

B. Look at the outside and/or inside color of the burger

C. Go by the texture or firmness of the burger

D. Look for the juices to run clear

E. The amount to time it has been cooking

When you are using a food thermometer on ground beef hamburger patties, what is the MINIMUM temperature you typically cook them to?

Why do you NOT use a food thermometer?

Are you aware of the cooked internal temperature at which ground beef is considered safe to eat?

What temperature?

When using a food thermometer on ground beef hamburger patties, how often would you say you cook them to 160 degrees or higher?

Using a 0 to 10 scale, where "0" equals NOT AT ALL CONCERNED, and "10" equals EXTREMELY CONCERNED, how would you rate your overall level of concern with the SAFETY of the ground beef you eat?

What is it in ground beef that concerns you in terms of its safety, what worries you specifically?

Using the same scale, where " 0 " is NOT AT ALL CONCERNED and "10" is EXTREMELY CONCERNED, how would you rate your level of concern with each of the following? Please use the full range of the scale to show differences; the higher the number, the more concerned you are. When cooking ground beef hamburger patties yourself, how much control do you feel you have over how safe it is to eat? Would you say:

For each of the following statements, please tell me whether you STRONGLY AGREE, MILDLY AGREE, NEITHER AGREE NOR DISAGREE, MILDLY DISAGREE, or STRONGLY DISAGREE with that statement.

A. Using a food thermometer to measure the internal temperature is the only way to be sure that a burger is done and safe to eat

B. Color is a reliable indicator that a burger is done and safe to eat

C. Texture and firmness are reliable indicators that a burger is done and safe to eat

D. As long as the juices from the burger run clear, it is safe to eat

E. The amount of time the burger has been cooking is a reliable method for determining if a burger is done and safe to eat

Do you ALWAYS, OFTEN, SOMETIMES, RARELY, or NEVER use a food thermometer when cooking any of the following other types of foods for safety?

Do you have a food thermometer in your home?

What type of food thermometer to you use most often?

How long have you owned a food thermometer?

Did you purchase your food thermometer or did someone else buy it or give it to you?

Why did you purchase it?

Now I have just a few questions about advertising you may have noticed. First, in the past 6 months or so, have you read, seen, or heard any advertising related to FOOD safety issues?

What was the main message of this advertising? What do you recall, specifically? Anything else?

Can you tell me who sponsored this advertising? 


\section{TABLE 1. The " $160^{\circ}$ is Good" campaign phone survey questionnaire (cont.]}

Questions

During the past 6 months or so, have you read, seen, or heard any advertising specifically related to BEEF safety?

What was the main message of this advertising? What do you recall, specifically? Anything else?

Can you tell me who sponsored this advertising?

Where did you see or hear this advertising?

What is your marital status?

Do you have any children under the age of 18 in your household?

Including yourself, how many people live in your household?

Are you currently

What is the highest level of education you have had the opportunity to complete?

Which of the following BEST describes your race? You can choose all that apply.

Considering all wage earners for your household, would your total household income, before taxes, be under or over $\$ 40,000$ per year?

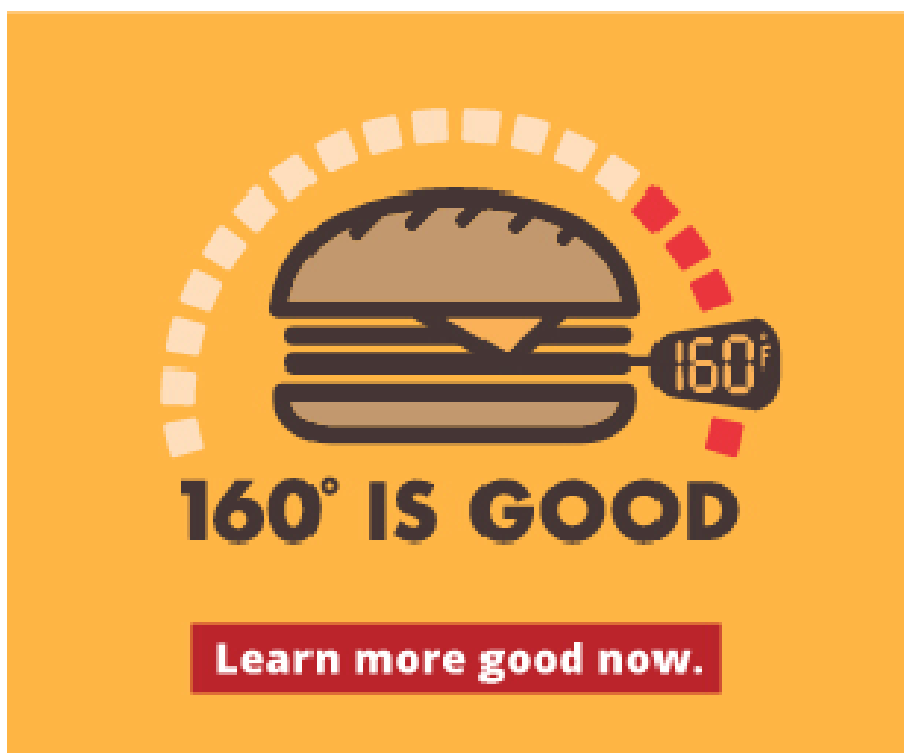

FIGURE 1. Banner from the " $160^{\circ}$ is Good" campaign.

were listened to or that the banner, picture, and/or video were seen. This total included 3,174,418 digital impressions (from online advertising). Radio PSA were played on the top seven radio stations in Fayetteville a total of 2, 292 times during the entire campaign. Based on marketing industry metrics, it was anticipated that there were $8,328,300$ radio impressions. This equates to a $73.2 \%$ reach into the Fayetteville market and estimates that ca. $73 \%$ of the population was likely to hear the " $160^{\circ}$ is good" message ata least one time, with an individual hearing the message some 33 times between Memorial Day and Labor Day of 2017. The total cost of the campaign was ca.
$\$ 200,000.00$ USD, with $\$ 83,000.00$ directed toward content development, strategy, design, and phone evaluation and the remaining $\$ 117,000.00$ directed towards purchasing media (inclusive of all radio, digital, and movie theater spots).

Part 1. Campaign evaluation - phone survey

A structured, random-dial telephone survey, utilizing both landlines and cellular lines within the 910 area code of Fayetteville, N.C., was conducted by an outside marketing agency both before and after the launch of the " $160^{\circ}$ is Good" campaign. As is done in food-safety related national phone 


\section{TABLE 2. Percent (\%) of respondents per location interviewed by phone}

\begin{tabular}{c|c|c}
\hline Location (Zip Code) & \multicolumn{2}{|c}{ \% of Total Sample } \\
\hline & $\begin{array}{c}\text { Pre-campaign } \\
(\mathbf{n}=305 \text { respondents })\end{array}$ & $\begin{array}{c}\text { Post-campaign } \\
(\mathbf{n}=\mathbf{3 0 5} \text { respondents })\end{array}$ \\
\hline 28303 & 17 & 15 \\
\hline 28304 & 16 & 17 \\
\hline 28305 & 4 & 22 \\
\hline 28306 & 20 & 17 \\
\hline 28311 & 17 & 27 \\
\hline 28314 & 26 & \\
\hline
\end{tabular}

surveys conducted on a regular basis by the Department of Health and Human Services, Food and Drug Administration (DHHS FDA; 18), different formats for survey questions were used to assess the quality, content, and impact of the " $160^{\circ}$ is Good" campaign (Table 2), such as multiple choice, short response, and open-ended free response questions, to make it less daunting for respondents to answer questions and to allow respondents to expand upon their opinions and experiences if inspired to do so. These questions focused on respondents' perceptions of beef food safety, thermometer usage, and food/beef handling practices. A minimum of 300 respondents were needed for both the pre- and post-campaign phone surveys (i.e., $\geq 600$ total respondents, with no duplicate numbers used for pre- and/ or post-campaign surveys). With a sample size of at least 300 respondents within the target area population of ca. 210,000 citizens, the confidence level for the results are $95 \%$, with a 5.61 confidence interval (29). Respondents were residents of the test market area who prepared meals at home and who specifically cooked burgers. The phone surveys were conducted on behalf of the contracted marketing/advertising company by an independent third-party research marketing firm, and the results were provided to the STEC CAP campaign development team. According to Steber (34), a phone survey should last ca. 15 $\mathrm{min}$. The baseline pre-campaign survey was completed in May of 2017, just prior to the launch of the " $160^{\circ}$ is Good" campaign, as a method to uncover current beliefs and behaviors associated with cooking beef burgers. The postcampaign phone survey was conducted in September of 2017, ca. two weeks after the campaign ended, to measure advertising effectiveness and visibility as well as to identify any attitude or behavioral changes that may have occurred as a result of the campaign.

\section{Demographic characteristics of respondents}

As detailed in Table 3, respondent characteristics consisted of age group; gender; marital status; number of children under age 18 in household; number of people in household; employment status; Hispanic, Latino, or Spanish; race; education level, and household income. There were no significant differences in the demographic characteristics between the pre- and post-campaign respondents and any shifts in attitudes or behaviors were therefore not likely due to sample fluctuations but rather to real changes that occurred in the population surveyed.

\section{Conduct of phone interview}

All phone calls emanated from the central interviewing facilities of the third-party independent research marketing firm. This firm accessed a database of landline and cellular numbers available from telephone companies and called potential participants until the target sample of at least 300 fully completed surveys was reached for both the preand post-intervention surveys. Calls were recorded and quality control conducted to ensure that recorded answers in the data collection forms were accurate. Only trained and experienced interviewers dialogued with respondents on phone calls and collected the data so as to achieve the high-quality, reliable, and valid information necessary for research purposes (19). Each interviewer was fully briefed on the proper administration of the questionnaire prior to respondent contact. Also, supervisors monitored interviews while in progress to ensure accuracy and completeness of the data being collected.

\section{Data analyses}

The independent research marketing firm collected all phone survey data and imported these data in tabular form into Excel (Microsoft, Redmond, WA). This third-party 


\section{TABLE 3. Pre-campaign vs. post-campaign sample demographic characteristics}

Percent (\%) of total respondents

Characteristics

Pre-campaign (305 respondents)

Post-campaign (305 respondents)

Age group

\begin{tabular}{l|c|c}
\hline 18 to 24 & 5 & 3 \\
\hline 25 to 34 & 9 & 9 \\
\hline 35 to 44 & 20 & 23 \\
\hline 45 to 54 & 23 & 21 \\
\hline 55 to 64 & 21 & 20 \\
\hline $65+$ & 22 & 20 \\
\hline
\end{tabular}

Gender

\begin{tabular}{l|c|c}
\hline Male & 39 & 41 \\
\hline Female & 61 & 59 \\
\hline
\end{tabular}

Marital status

\begin{tabular}{l|l|c}
\hline Single, Never Married & 16 & 18 \\
\hline Married/Partner & 64 & 63 \\
\hline Widowed/Divorced/Separated & 20 & 19
\end{tabular}

Children under age 18 in household

\begin{tabular}{l|l|l}
\hline Yes & 37 & 61 \\
\hline No & 61 & 39 \\
\hline
\end{tabular}

Number of people in household

\begin{tabular}{l|l|l}
\hline One & 11 & 13 \\
\hline Two & 27 & 36 \\
\hline Three & 31 & 20 \\
\hline Four & 18 & 17 \\
\hline Five or more & 13 & 14 \\
\hline
\end{tabular}

Employment Status

\begin{tabular}{|c|c|c|}
\hline Employed outside home & 45 & 47 \\
\hline Self-employed & 9 & 4 \\
\hline Not employed/looking & 4 & 6 \\
\hline Homemaker & 6 & 2 \\
\hline Student & 2 & 4 \\
\hline Military & 3 & 23 \\
\hline Retired & 27 & 4 \\
\hline Unable to work/disabled & 4 & 7 \\
\hline Hispanic, Latino, Spanish & & 93 \\
\hline Yes & 6 & \\
\hline No & 94 & 9 \\
\hline
\end{tabular}

Continued on next page. 
TABLE 3. Pre-campaign vs. post-campaign sample demographic characteristics (cont.)

\begin{tabular}{|c|c|c|}
\hline \multirow[b]{2}{*}{ Characteristics } & \multicolumn{2}{|c|}{ Percent (\%) of total respondents } \\
\hline & Pre-campaign (305 respondents) & Post-campaign (305 respondents) \\
\hline \multicolumn{3}{|l|}{ Race } \\
\hline White/Caucasian & 60 & 62 \\
\hline Black/African-American & 36 & 32 \\
\hline American Indian/Alaskan & 6 & 5 \\
\hline Other & 2 & 3 \\
\hline \multicolumn{3}{|l|}{ Education Level } \\
\hline High school or less & 14 & 13 \\
\hline Some college & 18 & 24 \\
\hline Trade/Technical & 4 & 4 \\
\hline Associate’s degree & 17 & 14 \\
\hline Bachelor's degree & 27 & 25 \\
\hline Post graduate degree & 20 & 20 \\
\hline \multicolumn{3}{|l|}{ Household Income } \\
\hline Under $\$ 25,000$ & 9 & 10 \\
\hline$\$ 25,000-\$ 39,999$ & 12 & 15 \\
\hline$\$ 40,000-\$ 59,999$ & 20 & 19 \\
\hline$\$ 60,000-\$ 100,000$ & 34 & 26 \\
\hline Over $\$ 100,000$ & 25 & 30 \\
\hline
\end{tabular}

contractor then compared the pre- vs. post-campaign responses to detect changes in attitudes, beliefs, and behaviors regarding food safety, using paired $t$-tests. When dealing with self-reported behaviors and perceptions during phone calls, as for the present study, participants had the opportunity to lie to the interviewers and/or to provide responses that were untrue. Since it was not possible to determine with any degree of certainty which responses were true or untrue, all responses were coded and analyzed as being true.

\section{Part 2. Campaign evaluation - focus groups}

After the " $160^{\circ}$ is Good" campaign concluded and all phone survey data had been collected, focus groups were assembled in the Fall of 2017 to gather more in-depth information on perceptions, attitudes, and self-reported behavior changes, as well as to gain insight into message content and quality. Although focus groups can be conducted prior to campaign development, the " $160^{\circ}$ is Good" campaign was seen as a pilot study for a larger food safety campaign under development that will be national in scope, and for this purpose conducting focus groups post-campaign was useful for gleaning research insights that were not uncovered during the standard telephone interviews. The objectives, methods, and justification for this research were reviewed and approved by the North Carolina State University Institutional Review Board (IRB) Protocol \#12341. Focus groups were recruited and conducted essentially as described (20). Six focus groups were conducted because $90 \%$ of all themes are discoverable within three to six focus groups (11). Focus groups are composed of four to twelve people, and meetings are conducted in varying locations to minimize any influence by internal and external factors and because participants would unlikely be unfamiliar with one another (17). The current research is rooted in interpretive and constructivist epistemological perspectives to provide description, understanding, and interpretation of the perceptions of consumers related to the " $160^{\circ}$ is Good" campaign. Epistemological perspectives provide framework for describing and analyzing the varying views and information rooted in qualitative research that derive from the four primary epistemological perspectives identified in research: (i) philosophical analysis, the nature of knowledge, and how it relates to truth, belief, and justification, (ii) issues related to skepticism, (iii) nature, scope, and 
source of knowledge and justified beliefs, and (iv) criteria for justification as well as knowledge $(1,23)$.

\section{Focus group sample selection and recruitment}

The one-hour focus groups were conducted between November and December of 2017 at the following locations: (i) Fayetteville, NC (location of the campaign), (ii) Souderton, PA, and (iii) Charlotte, NC. Participants were recruited through Cooperative Extension local school Listservs and promoted via Facebook (Menlo Park, CA; http://www.facebook.com), Twitter (San Francisco, CA; http://www.twitter.com) and Craigslist (San Francisco, CA; http://www.craigslist.com) advertisements. Recruits were guided to a Google Form (Mountain View, CA; https:// www.google.com/forms/) where they signed up for their preferred time slot. Twelve slots were available for each focus group in anticipation that some participants might not show up on the day of the focus group meeting. In total, groups ranged in number from 6 to 11 participants, with a final total of 44 participants. Each participant received a $\$ 20$ gift card to a retailer for participation.

\section{Data collection}

The focus group protocol (Table 4) was semi-structured, and the atmosphere was extremely informal to promote conversation and openness in the dialogue. Semi-structured discussions are recommended when there is only a single chance or opportunity to communicate with a group (2). Semi-structured discussions provide a clear set of talking points that are reliable and that meet the research objectives but that also allow participants the freedom to express their thoughts in their own terms. The protocol consisted of nine open-ended questions that guaranteed that the moderator covered vital topics and questions during the conversation while still allowing for discussion and open sharing. The focus group protocol introduced the participants to the campaign and then covered topics including effective food safety advertisements, motivation to use a food thermometer, thoughts on each component of the campaign, and the overall impact of the campaign. In addition, the moderator asked the group, "If you were to design a successful and effective food safety campaign, how it would look and what would the components be?" A researcher trained in qualitative analysis and evaluation carried out the focus groups.

\section{Data analyses}

The focus group conversations were audio recorded (WS700M digital recorder; Olympus, Center Valley, PA), with written consent of all participants, and then transcribed via TranscribeMe (Oakland, CA; http://www.transcribeme. com), a high-quality speech-to-text service provider. When transcriptions were completed, the data were coded to determine common themes, using constant comparison analysis (10). The data were divided into units determined by participant quotations, attached to a code that was grouped into categories, for example doneness; then themes were developed that expressed each of the categories, for example, the correlation between color and internal burger temperature. This emergent-systematic focus group data analysis design promotes exploratory and verified analysis of data sets when multiple focus groups are being analyzed (35). Additionally, the primary researcher kept a reflexive research diary throughout the data analyses process to document the coding, themes, patterns, and cluster decisions being made. A reflexive research diary acknowledges the problem of bias in qualitative research, as stated in the positionality statement (25). One limitation of focus groups is that the raw data recordings cannot be made available because of the need to keep identities anonymous. The reflexive diary is for personal use in analyzing the data and is not usually made public because it includes first judgments and how the researcher goes about avoiding those judgments (25).

\section{RESULTS AND DISCUSSION}

The data shared herein was a key accomplishment of the STEC CAP (24). By both intent and design, ca. one-third of the monies awarded to STEC CAP were directed towards education/outreach efforts and ca. $\$ 200 \mathrm{~K}$ of these monies were used to develop and disseminate a message for the masses related to proper use of a thermometer to measure doneness of ground beef. In partnership with a national marketing/advertising company, phone surveys and focus groups were used to assess the effectiveness of the " $160^{\circ}$ is Good" campaign and the quality, content, and delivery of the attendant logo and message. Pre- and post-campaign phone surveys are a reliable strategy to gather insight when measuring outcomes after a treatment or intervention has occurred (30). Likewise, focus groups are an effective method to discover demographic-relevant information via group sessions that are interactive and informative to both participants and the facilitator: participants can speak freely (and anonymously) about the subject matter and offer their opinions and in so doing contribute to what the survey is attempting to discover $(9,10)$.

\section{Part 1. Phone surveys}

Dial phone surveys are effective and useful at gathering information for geographically-dispersed samples, collecting information on health-related behaviors and attitudes, and reducing data transfer errors that can occur with paper surveys (3). Pre-campaign (baseline) survey phone calls averaged $13.3 \mathrm{~min}$ in length, and post-campaign (evaluation) survey phone calls averaged $17.2 \mathrm{~min}$ in length. Once screened for inclusion in the phone survey, respondents provided information on how often they cooked burgers (Fig. 2). About one-third stated they cooked burgers ca. two to three times per month, ca. one-fourth cooked burgers about once per week, and another one-fourth did so ca. once per 


\section{TABLE 4. The " $160^{\circ}$ is Good" focus group moderator guide protocol}

\section{Questions}

Familiarization with the campaign message that we will be discussing. As I scroll through the website, please take it all in:

This video was played during the previews at the beginning of movies at movie theatres.

The audio clips were played on basic FM radio stations as well as the music app Pandora.

The logo was shown as a banner ad along the top of websites.

Website was linked to social media such as Facebook and Twitter.

Additionally, the quiz that is located on the website can be found in your packet for you to review as well.

\section{Option A:}

As a way to introduce yourselves you can say your name and what you think the purpose of the advertisements was.

What were your first impressions of the advertisements?

Did you like the advertisements?

Did you dislike the advertisements?

What stood out to you?

\section{Option B:}

Once again, I'd just like to get a head count of how many of you recognized this campaign previously.

So, as a way to introduce yourselves you can say your name and if you saw or heard any of these advertisements this past summer?

If so, where did you see or hear it?

Was there anything presented in the campaign that surprised you?

1. Now that we've reviewed the campaign I would like you to state what you think food safety means and the role it plays in your life.

a. What do you think of when you hear the words food safety?

b. Does this campaign match what you think of when you hear food safety?

c. How could this campaign portray food safety effectively?

i. Effective:

1. How would you define successful in this scenario?

2. In this regard, effective relates to hearing or seeing the messaging and it caused a change in thought or behavior in regards to thermometer use.

2. What do you feel would be effective about these advertisements in regards to convincing you to buy and use a food thermometer when cooking meat and why?

a. What do you feel would be ineffective about these advertisements in regards to convincing you to buy and use a food thermometer when cooking meat and why?

b. What type of thermometer would you buy and why?

c. What would you use it on and why?

i. * Overall feedback on campaign messaging as a whole

3. In your opinion, what food safety messaging would be effective in convincing you to buy and use a food thermometer when cooking meat and why?

a. In your opinion, what food safety messaging would be ineffective in convincing you to buy and use a food thermometer when cooking meat and why?

b. What did you like or not like about the $160^{\circ}$ Is Good food safety campaign?

i. * Overall feedback about food safety messaging in general

4. If you own a food thermometer, what motivated you to get and use it? Why?

a. If you do not own a food thermometer, what are the reasons you don't feel the need to purchase and use one and why?

b. What is it that turns you away from using a food thermometer?

Now we have some questions regarding the results we gathered through a phone survey where advertisements were released:

- The results from the phone survey depicted that after seeing the advertisements, $23 \%$ of respondents said they started using a food thermometer or already use a food thermometer. Do you agree with this statement?

Why do you think the other $77 \%$ did not or will not purchase a food thermometer?

What do you believe could be done to convince them to purchase and use a food thermometer? 


\section{TABLE 4. The " $160^{\circ}$ is Good" focus group moderator guide protocol (cont.)}

\section{Questions}

- The results from the phone survey depicted that $81 \%$ of respondents did not recall seeing, hearing, or reading any beef safety advertising. Why do you think that is?

What do you think could be done to reach a larger audience?

- The results from the phone survey depicted that $15 \%$ of respondents use a food thermometer to determine when a beef hamburger is done cooking.

Why do you think that is?

What other methods do you think people are using?

Why would they use these methods?

How could messages be designed to show the importance of using a food thermometer?

5. What are your thoughts on the

a. Movie theatre pre-roll clip

i. Do you feel this advertisement method is successful?

ii. What methods do you believe would be more successful in reaching more people and why?

b. Audio clips (either radio or Pandora)

i. Do you feel this advertisement method is successful?

ii. What methods do you believe would be more successful in reaching more people and why?

c. Logo

i. Do you feel this advertisement method is successful?

ii. What methods do you believe would be more successful in reaching more people and why?

d. Website

i. Do you feel this advertisement method is successful?

ii. What methods do you believe would be more successful in reaching more people and why?

e. Quiz

i. Do you feel this advertisement method is successful?

ii. What methods do you believe would be more successful in reaching more people and why?

f. Successful:

i. How would you define successful in this scenario?

ii. In this regard, successful relates to hearing or seeing the messaging and it caused a change in thought or behavior in regards to thermometer use.

6. Which of your food safety behaviors do you feel would be most affected by the advertisements and why?

a. Which do you feel were least affected and why?

b. Were there food safety messages incorporated that you had not previously considered?

7. What methods could we use to convey the importance of purchasing and using a food thermometer beyond these?

8. How would you describe the overall impact of these food safety advertisements?

a. On yourself?

b. On others who may also be introduced to the campaign?

9. If we were to design a successful and effective food safety campaign together, right now, how would it look? You can use the paper and pen in front of you to create lists and designs as we share as a group.

a. What would it include?

b. What would it not include?

i. Information wise

c. How would it be advertised?

\section{Probing questions:}

Would you explain further?

- Would you say more?

- Please describe what you mean.

- Is there anything else that you can add?

- Is there anyone else that agrees with that statement?

- Is there anyone that disagrees with that statement?

-What do you mean by successful? Flip the question back to the group.

- Why is using a food thermometer important? 


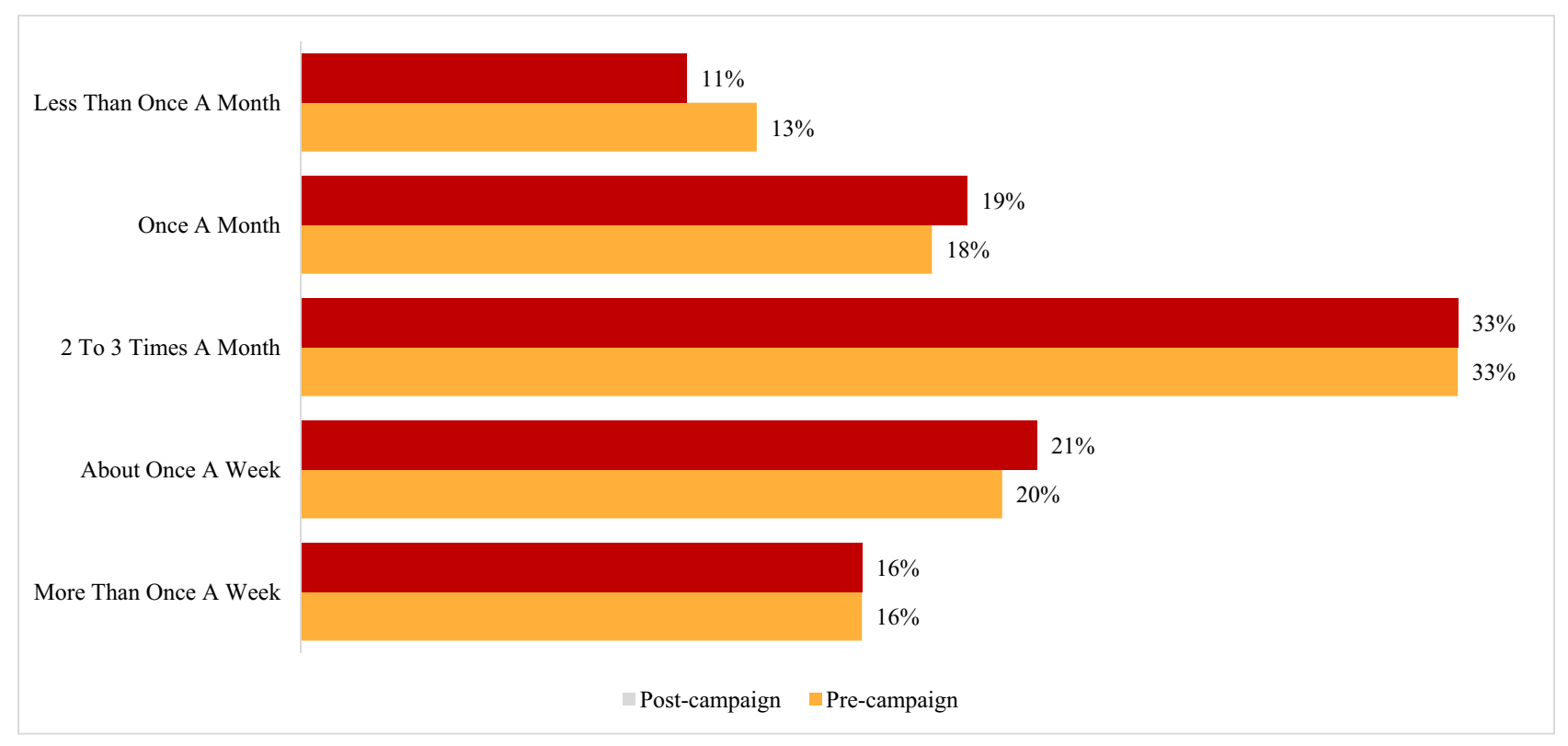

FIGURE 2. Frequency (\%) with which household cooks beef burgers.

month. Responses were similar both pre- and post-campaign. When asked to describe, in their own words, how they typically determine when burgers are done (Table 5), the most common post-campaign reply (ca. 33\%, 100 of 305 respondents) was "cut it open," a significant increase from the pre-campaign reply (ca. 16\%, 48 of 305 respondents) for this method of determining doneness. The next most common reply (ca. 25\%, 76 of 305 respondents) was looking at the "outside or inside color," a significant decrease from the pre-campaign reply (ca. 39\%, 119 of 305 respondents). "Use thermometer" and "Juices run clear" at ca. $13 \%$ to $16 \%$ were the next most popular responses, with essentially no differences between the pre- and post-campaign responses (Table 5) or between those who recalled ( $n=73$ of 305$)$ and those who did not recall ( $\mathrm{n}=233$ of 305 respondents) a food safety advertisement (Table 6). When the total sample was considered, results did not vary appreciably between preversus post-campaign, with ca. two-thirds of meal preparers indicating they "never" measure the internal temperature of a burger with a food thermometer when cooking (Fig. 3). A greater number of post-campaign respondents with recollection of the " $160^{\circ}$ is Good" campaign "always" used a food thermometer to determine if burgers were done (15\%), compared with their counterparts with no recall of this campaign (11\%).

Only $24 \%(n=72)$ of 305 post-campaign respondents recalled hearing or seeing " $160^{\circ}$ is Good" beef safety work products, and only $44 \%$ of post-campaign respondents recalled any advertising related to food safety. Additionally, $11 \%(n=12)$ of post-campaign respondents who recalled hearing or seeing a beef safety and/or " $160^{\circ}$ is Good" advertisement $(n=107)$ reported purchasing a new food thermometer, and $23 \%(n=25)$ of post-campaign respondents who recalled hearing or seeing a beef safety and/ or " $160^{\circ}$ is Good" advertisement $(n=107)$ had started using a thermometer when cooking burgers. Of those who recalled hearing or seeing a beef safety and/or " $160^{\circ}$ is Good" work product and who purchased a new food thermometer $(\mathrm{n}=$ 12), $75 \%(n=9)$ purchased a digital thermometer, $17 \%(n=$ 2) purchased a dial thermometer, and $8 \%(n=1)$ purchased a glass thermometer. As both a consequence and constraint of how the survey was structured, we were not able to compare the self-reported purchasing behavior of those who recalled the messages disseminated as part of the " $160^{\circ}$ is Good" campaign with the behavior of those who did not. That being said, estimates of thermometer ownership in the U.S. in 2016 were $67 \%$ of the population $(n=2,313)$, with these same individuals reporting never using the tool to evaluate the temperature of beef hamburger patties (18). Those who recalled a beef safety work product remembered the message being about "making sure burgers were cooked or done," "temperature concerns," and other topics (Table 7). Overall, very few respondents recalled any of the " $160^{\circ}$ is Good" beef safety campaign messaging, and only a slight increase in thermometer usage could be attributable to the " $160^{\circ}$ is Good" campaign.

When asked to rate their overall concern with the safety of the ground beef they eat, about one-half of respondents, preand post-campaign, gave a rating of 7 or higher, indicating at least a moderate level of concern (with 37\% highly concerned; 9-10 rating). More specifically, respondents who rated their level of concern as " 4 or higher" pre-campaign (n $=215)$ and post-campaign $(n=211)$, volunteered that these concerns were often related to bacteria, E. coli, and other 


\section{TABLE 5. How respondents determine when beef burgers are done}

\begin{tabular}{l|c|c} 
& \multicolumn{2}{|c}{ Percent (\%) of Total Sample } \\
\hline Volunteered Responses & Pre-campaign (305 respondents) & Post-campaign (305 respondents) \\
\hline Cut it open & 16 & 33 \\
\hline Outside/Inside color & 39 & 25 \\
\hline Use thermometer & 14 & 16 \\
\hline Juices run clear & 13 & 14 \\
\hline Timing & 9 & 6 \\
\hline Texture/Firmness/By touch & 7 & 6 \\
\hline By appearance (Unspecified) & 5 & 6 \\
\hline By experience & 3 & 4 \\
\hline When no juices come out & 1 & 1 \\
\hline Temperature (Unspecified) & 3 & 2 \\
\hline Other & 2 & 1 \\
\hline Don't know/nothing & -- & \\
\hline
\end{tabular}

\section{TABLE 6. How respondents (those who did or those who did not recall a food safety advertisement) determine when beef burgers are done}

\begin{tabular}{l|c|c} 
& \multicolumn{2}{|c}{ Percent (\%) of Total Sample } \\
\hline Volunteered Responses & $\begin{array}{c}\text { Recalled a food safety advertisement } \\
(\mathbf{n}=72 \text { respondents) }\end{array}$ & $\begin{array}{c}\text { Did not recall a food safety } \\
\text { advertisement } \\
\text { (n 233 respondents) }\end{array}$ \\
\hline Cut it open & 32 & 33 \\
\hline Outside/Inside color & 29 & 24 \\
\hline Use thermometer & 19 & 15 \\
\hline Juices run clear & 4 & 17 \\
\hline Timing & 4 & 9 \\
\hline Texture/Firmness/By touch & 7 & 6 \\
\hline By appearance (Unspecified) & 6 & 4 \\
\hline By experience & 11 & 4 \\
\hline When no juices come out & 4 & -- \\
\hline Temperature (Unspecified) & 1 & 3 \\
\hline Other & 1 & 1 \\
\hline Don't know/nothing & 1 & \\
\hline
\end{tabular}

contaminants or illnesses. However, the majority of meal preparers were not aware of the internal temperature at which ground beef is considered safe to eat: $68 \%$ pre-campaign ( $\mathrm{n}$ $=201)$ and $65 \%$ post-campaign $(\mathrm{n}=195)$ (Table 8$)$. Also, among those not using a food thermometer when cooking burgers, pre-campaign $(\mathrm{n}=78)$ and post-campaign $(\mathrm{n}=$
64), no statistically significant shifts were found in the preversus post-campaign results when gauging the minimum temperature at which ground beef burgers should be cooked. Of those who do not always use a thermometer, $40 \%$ of precampaign and $41 \%$ of post-campaign respondents attributed their response to perceptions that "it is not needed" or 


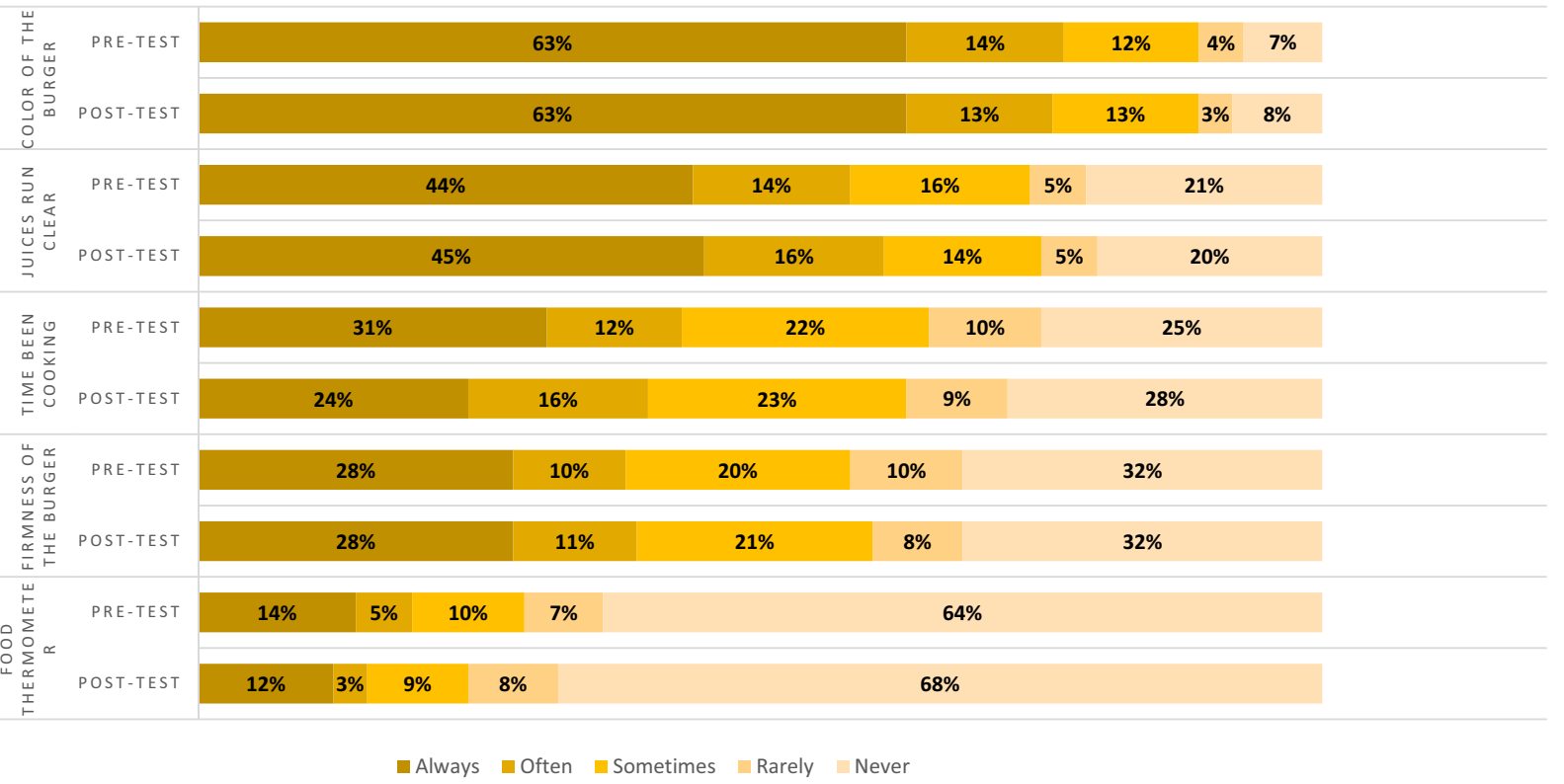

FIGURE 3. Techniques used to determine doneness in beef burgers.

\section{TABLE 7. Awareness and cooking to internal temperature at which beef burgers are} considered safe to eat

\begin{tabular}{l|c|c} 
& \multicolumn{2}{|c}{ Percent $(\%)$ of Total Sample } \\
\hline Responses & $\begin{array}{c}\text { Pre-campaign } \\
(\mathrm{n}=296 \text { respondents })\end{array}$ & $\begin{array}{c}\text { Post-campaign } \\
(\mathbf{n}=300 \text { respondents })\end{array}$ \\
\hline Aware and under $160^{\circ} \mathrm{F}$ & 7 & 6 \\
\hline Aware and $160^{\circ} \mathrm{F}$ & 9 & 14 \\
\hline Aware and $165^{\circ} \mathrm{F}$ & 5 & 7 \\
\hline Aware and over $165^{\circ} \mathrm{F}$ & 11 & 65 \\
\hline Not aware & 68 & 8 \\
\hline
\end{tabular}

they feel they know when "it is done because they are experienced." All of this being said, at least one-third of meal preparers, $32 \%$ of pre-campaign and $35 \%$ of post-campaign respondents, feel they have "at least a moderate amount of control" over how safe it is to eat the beef burgers they cook themselves, and nearly one-half, $45 \%$ of pre-campaign and $44 \%$ of post-campaign respondents, believe they have "a great deal of control" in this regard.

\section{Part 2. Focus groups}

Messages related to food safety are most effective when meaningful to the intended audience, populated with accurate information, delivered repeatedly, and distributed at appropriate times (14). To gain insight on the effectiveness of both the content and cosmetic components of the " $160^{\circ}$ is Good” logo, slogan, and campaign, we hosted and conducted six one-hour focus groups in the Fall of 2017. While there were contradictory perceptions and opinions on many of the components of the campaign, the consensus from focus group participants was that the " $160^{\circ}$ is Good" campaign would not likely evoke or promote behavioral change(s) related to food thermometer use on burgers when grilling. Overall, participants assessed the campaign logo and website as informational, concise, and educational in a fun way. "It was to the point, colorful, and easy to read. It also had a lot of facts without sounding like you were reading a journal." However, from other feedback and insights gleaned from focus group participants, we also learned that participants 


\section{TABLE 8. Awareness and cooking to internal temperature at which ground beef is considered safe to eat from respondents who did or did not recall a food safety advertisement}

\begin{tabular}{l|c|c} 
& \multicolumn{2}{|c}{ Percent $\%)$ of Total Sample } \\
\hline Responses & $\begin{array}{c}\text { Recalled a food safety advertisement } \\
(\mathbf{n}=\mathbf{7 0} \text { respondents })\end{array}$ & $\begin{array}{c}\text { Did not recall a food safety } \\
\text { advertisement } \\
(\mathbf{n}=230 \text { respondents })\end{array}$ \\
\hline Aware and under $160^{\circ} \mathrm{F}$ & 6 & 7 \\
\hline Aware and $160^{\circ} \mathrm{F}$ & 17 & 12 \\
\hline Aware and $165^{\circ} \mathrm{F}$ & 17 & 4 \\
\hline Aware and over $165^{\circ} \mathrm{F}$ & 10 & 70 \\
\hline Not aware & 50 & 7 \\
\hline
\end{tabular}

would not voluntarily visit the " $160^{\circ}$ is Good" website to search for additional information. This suggests that the main message of the campaign should be included directly on the primary work product (the banner, radio ad, or theater pre-roll) rather than on a secondary platform such as was used to direct the target population to a website. While there were positive and negative reactions to different portions of the " $160^{\circ}$ is Good" campaign, neither the content nor the delivery vehicle served as the catalyst for large-scale behavioral change(s) among the majority of the population exposed to this message via sight and/or sound.

The first and most prevalent theme articulated by focus group participants was the presumption of a correlation between burger internal temperature and color. There was also confusion about the cooking temperature for other species of meat (e.g., poultry) and about the comparative level of doneness on the scale of rare, medium rare, medium, medium well, and well done. Focus group participants stated, "Overall I think [the campaign message] just leaves more questions than answers," "Is $160^{\circ}$ just good for burgers?," "Does one-hundred sixty degrees mean medium well?," "Could one-hundred sixty degrees be for any ground meat products?." Other participants mentioned, "I don't think there was enough in the campaign to tell me what to do. How do I temp the food?" and "There is a little mixedmessaging to me." A potential shortcoming of the campaign was extrapolation of the message on proper thermometer use for grilled burgers to other foods by some participants. More specifically, "Does this information apply to all other foods, or is it just beef?" Along very similar lines, there was also general confusion related to the overall purpose of the campaign (e.g., "Why is it only focused on beef burgers and grilling?"), as well as general curiosity about other meat internal temperatures. The objective of the campaign was to inform consumers of proper thermometer use and cooking temperaures, it was not to sell thermometers or to scare people away from eating burgers. For example, participants stated, "I think the goal was to sell meat thermometers, right? I don't know that it's as educational as it is a sales pitch for a good reason to buy a meat thermometer so you don't poison your family." So, by developing and disseminating an informative, but highly focused, message, interest was generated around safe cooking of other ground meats and correlations were sought for common cooking terms which, in turn, may have partially blurred the main message. Lastly, regarding the 30-s theater pre-roll video, there was high agreement that a movie theater was a great location for health campaign messaging, "A movie theatre is a good venue because it's a captive audience." Along these same lines, video screens on gas pumps that people watch when pumping gas would be another very good opportunity to share a health message with a captive audience.

In contrast, participants were not fond of the radio advertisement; they thought it did not make sense and that it was neither funny nor scary without the video and therefore would not motivate them to visit the website to learn more about food safety. One participant stated, "Had I not seen the video advertisement first, the radio spots would have been a little ambiguous, and it didn't really talk through the positive aspect of the food safety message." Another participant stated, "I might not change the station when the radio advertisement came on, but I definitely wouldn't go look up the website when I got home." This calls into question whether radio advertisements in general are useful for motivating the public to go to websites to learn more or for changing behaviors. More data is also needed to assess the extent to which people pay attention to radio advertisements in general.

Participants also generally had negative reactions and expressed skepticism about the banner advertisement not being catchy enough to cause viewers to risk clicking on a scam. One participant shared that "[ the banner 
advertisement] doesn't have that eye-catching appeal and there's nothing there to validate that is a safe something to click on." Participants also shared that, "I'm just leery about clicking on things" and "I just won't click on anything unless I know specifically if it's associated with a well-known website that it will take me to." With the virus, scams, and safety concerns surrounding the Internet currently, most people are hesitant to click on banner advertisements on webpages. Therefore, banner advertisements are assumed to not be a very reliable way to reach consumers directly.

Suggestions from the focus groups for moving forward included advertising on social media because that is where most of the population can be reached; placing the video advertisement on monitors located in the meat department of grocery stores; including a food thermometer coupon as a portion of the advertisement; placing the advertisements on grocery store phone apps and online ordering websites; placing a " $160^{\circ}$ is Good" sticker on ground beef packages; educating kids, who will then encourage their parents to use a food thermometer; providing an informational pamphlet on proper cooking and thermometer use with a grill purchase; and encouraging television chefs and recipe websites to include internal temperatures in their presentations and to promote the campaign. These suggestions provide insight into where consumers themselves feel food safety advertising would be most effective in reaching the population.

\section{Overview and significance of findings}

Scientifically sound regulations and validated control strategies implemented since the early 1990s by food safety professionals at all points along the beef chain continuum have lowered the occurrence and load of STEC on beef. However, the current numbers and severity of STEC infections attributable to beef, along with the frequency and volume of recalls due to raw beef contaminated with STEC, provide justification and urgency for continued research to further lower the prevalence and levels of this bacterium in beef. Also needed are additional messaging and outreach efforts related to the requirements for and benefits of proper cooking and thermometer use to mitigate risk for end users (consumers). To this end, the entirety of the " $160^{\circ}$ is Good" campaign resulted in an estimated 11,502,718 million impressions within a 16-week span within and near Fayetteville, NC. The 8,328,300 radio impressions equate to a $73 \%$ reach in the Fayetteville market, with almost twothirds of the residents within the six target zip codes seeing or hearing a work product/advertisement at least one time (data not shown). Thus, it seems likely that the targeted market was adequately saturated with the message. The absence of statistically significant differences in thermometer use between pre- and post-campaign persons queried via phone would suggest that perhaps the message content, format, and/or method and timing of delivery were not optimal. In fact, a primary take-home message from focus group participants was that delivery of the message to a captive audience, for example those attending a movie, was more desirable and effective than other modalities, especially radio spots. In retrospect, perhaps a far greater number of individuals should have been interviewed by phone both pre- and post-campaign, and perhaps only/primarily folks hearing or seeing the message should have been interviewed post-campaign to determine if they experienced changes in behavior from directly viewing or hearing the " $160^{\circ}$ is Good" work products/advertisements.

More effective campaign methods targeting large populations must be developed to better communicate the importance of using a digital food thermometer to determine doneness of burgers. Findings from the " $160^{\circ}$ is Good" campaign suggest that those who were able to recall this advertising did have increased awareness of the importance and need to use a food thermometer for food safety purposes. Therefore, response-efficacy surrounding food thermometer use was increased. Although the campaign influenced food safety behaviors, room for improvement is obvious. The more comfortable consumers are with talking about food safety and practicing safe food procedures, the more likely they are to exhibit safe food handling and preparation behaviors. Explanations for why " $160^{\circ}$ is Good" did not evoke sufficient emotion to persuade consumers to appreciably change their food safety behaviors may include the following: (i) it did not adequately emphasize the health risks of contracting a foodborne illness, (ii) message components were not relatable to the audience, or (iii) the audience did not engage with the campaign for whatever reasons, thus creating no emotional ties to the information. A food safety campaign should induce a strong emotion that will be remembered by consumers when they are grilling burgers so that they feel the need to use a food thermometer to check for doneness. Of note, a beef food safety campaign should not create a fear of the cattle and livestock industry, but instead should place emphasis on the importance and responsibility the consumer assumes once the raw beef product is in their possession during storage, preparation, and cooking. It is important for consumers to understand the role they play in their health and well-being rather than placing food safety concerns solely on the industry or regulatory authorities. Food safety advocates can help consumers realize this by stressing the responsibility consumers have to adopt food safety practices in their homes.

Our results highlight the limitations related to media campaigns that are focused on changing risky behaviors. Not only does it require market penetration of a message (which arguably occurred with $>11$ million impressions over a 16-week period by ca. 210,000 individuals living in the vicinity of Fayetteville, NC), but a campaign must include a message that has impact. While this campaign reached many people, it demonstrates the difficulty in measuring impact and the challenges of quantifying a change in 
practices/behavior. It is entirely possible that the message, or the media, or both that were chosen by the research team were not the best approaches to impact food safety related practices and behaviors. One of the challenges that food safety communicators have is that, unlike development of traditional media advertising campaigns, food safety message development is not focused on brand identification or selling more product. The most powerful insights found through this work are that message and media testing prior to campaign launch could lead to higher success, and that somehow melding the advertising world's approaches with the research world's intervention evaluation is a necessary task to explore in future campaigns.

This research provides insights into thermometer use on grilled beef burgers and attendant behavior changes due to a regional food safety campaign. Additional research is needed related to utilizing food safety campaigns to educate consumers on food safety behaviors, including further research on and message content and dissemination. Food safety advocates can also use this avenue of research to determine where consumer understandings of food safety concepts are incorrect or lacking and to subsequently educate them on such topics as/if needed. Future food safety campaigns should provide solutions for lowering the risks of contracting a foodborne illness, such as using a food thermometer, and also articulate the practical benefits of doing so, such as not over-cooking or drying out the food. Additionally, by tying food safety tips to the improved quality of food and the level of satisfaction with the food consumers are preparing, an emotion is tied to the behavior. Few people recognized, remembered, and grasped the information in the " $160^{\circ}$ is Good" campaign, suggesting that future food safety campaigns may benefit from more catchy, repetitive, and memorable elements. Such efforts would benefit from sharing information at locations where consumers commonly are found or spend idle time, such as while pumping gas, sitting in waiting rooms, and/or waiting for or riding in public transportation. Future efforts will also be directed to analyze the effects of making campaigns commonly available on packaging of food products, in grocery stores, on social media, and in other media outlets such as television and magazines. Food safety campaigns need to be extremely memorable, share the need to change behavior, and offer mechanisms to make that change. This study, at its core, provides a road map for doing so.

\section{ACKNOWLEDGMENTS}

Special thanks are extended to Frank Gallagher, Kyle Longacre, Stuart Marjoram, Michael Olenick, Brian Ruth, Sam Varano, and the students of the 2016 Design, Marketing, and Communications (DMC) Club of the Souderton Area High School (Souderton, PA), as well as Minh Duong (North Carolina State University), for their participation, assistance and/or technical expertise. This material is based upon work that is supported by the National Institute of Food and Agriculture, U.S. Department of Agriculture, under award number \#2012-68003-30155. Mention of trade names or commercial products in this publication is solely for the purpose of providing specific information and does not imply recommendation or endorsement by the U.S. Department of Agriculture. USDA is an equal opportunity provider and employer.

\section{REFERENCES}

1. Anonymous, 2019. Epistemology. Available at: https://en.wikipedia.org/wiki/Epistemology. Accessed on 23 September 2019.

2. Bernard, H. 1988. Research methods in cultural anthropology. Sage Publications, Newbury Park, CA.

3. Boland, M., M. R. Sweeney, E. Scallan, M. Harrington, and A. Staines. 2006. Emerging advantages and drawbacks of telephone surveying in public health research in Ireland and the U.K. BMC Publ. Health 6:208. doi:10.1186/1471-2458-6-208.

4. Byrne, C. M., D. J. Bolton, J. J. Sheridan, I. S. Blair, and D. A. McDowell. 2002. Determination of the effect of sodium lactate on the survival and heat resistance of Escherichia coli O157:H7 in two commercial beef patty formulations. Food Microbiol. 19:211-219.

5. Centers for Disease Control and Prevention. 2018. How common are STEC infections? Available at: https://www.cdc.gov/ecoli/general/index.html. Accessed 23 July 2019.

6. Chapman, B., J. Hochstein, A. Porto-Fett, K. Longacre, and J. Luchansky. 2019. Creation and implementation of a social marketing campaign for beef food safety. Abstracts of the Annual Meeting of the International Association for Food Protection. Supplement A to J. Food Prot. (P1-94), p. 106.

7. Cope, S. J. 2019. Evaluating the communication of food safety to consumers. M.Sc. Thesis. North Carolina State University, Raleigh, NC. Available at: https://repository.lib.ncsu. edu/ bitstream/handle/1840.20/36596/etd. pdf? sequence $=1$ \&isAllowed $=y$. Accessed 20 September 2019.

8. Currie, A., L. Hornish, J. Cutler, A. Locas, M.-C. Lavoie, C. Gaulin, E. Galanis, L. Tschetter, L. Chui, M. Taylor, F. Jamieson, M. Gilmour, C. Ng, S. Mutti, V. Mah, M. Hamel, A. Martinez, E. Buenaventura, L. Hoang, A. Pacagnella, D. Ramsay, S. Bekal, K. Coetzee, C. Berry, J. Farber, and The National Investigative Team. 2019. Outbreak of Escherichia coli O157:H7 infections linked to mechanically tenderized beef and the largest beef recall in Canada, 2012. J. Food Prot. 82:1532-1538.

9. Gaille, B. 2015. 12 pros and cons of focus groups. Available at: https://brandongaille. com/ 12-pros-and-cons-of-focus-groups/. Accessed 23 September 2019.
10. Glaser, B. G., and A. L. Strauss. 1967. The discovery of grounded theory: strategies for qualitative research. New York. Aldine de Gruyterlding.

11. Guest, G., E. Namey, and K. McKenna. 2017. How many focus groups are enough? Bui, an evidence base for nonprobability sample sizes. Field Meth. 29:3-22.

12. Hussein, H. S. 2007. Prevalence and pathogenicity of Shiga toxin-producing Escherichia coli in beef cattle and their products. J. Anim. Sci. 85:E63-72.

13. Jackson, C. J., M. D. Hardin, and G. R. Acuff. 1996. Heat resistance of Escherichia coli O157:H7 in a nutrient medium and in ground beef patties as influenced by storage and holding temperatures. J. Food Prot. 59:230-237.

14. Jacob, C., L. Mathiasen, and D. Powell. 2010. Designing effective messages for microbial food safety hazards. J. Food Control 21:1-6.

15. Juneja, V. K., O. P. Snyder, A. C. Williams, and B. S. Marmer. 1997. Thermal destruction of Escherichia coli O157:H7 in hamburger. J. Food Prot. 60:1163-1166. 
16. Kaspar, C., M. E. Doyle, and J. Archer. 2010. White paper on non-O157:H7 Shiga toxin-producing $E$. coli form meat and non-meat sources. Available at: http://fri.wisc.edu/ docs/pdf/FRI_Brief_NonO157STEC_4_10. pdf. Accessed 20 September 2019.

17. Krueger, R. A. 1994. Focus groups: a practical guide for applied research. Sage Publications, Newbury Park, CA.

18. Lando, A., L. Verrill, S. Liu, and E. Smith. 2016. 2016 FDA Food Safety Survey 49. Available at: https://www.fda.gov/downloads/ food/foodscienceresearch/ consumerbehaviorresearch/ucm529453.pdf. Accessed on 07 August 2019.

19. Lavrakas, P. J. 2008. Interviewer training. In Encyclopedia of survey research methods. Sage Publications, Thousand Oaks, CA. doi: $10.4135 / 9781412963947$.

20. Levine, K., M. Yavelak, J. B. Luchansky, A. C. S. Porto-Fett, and B. Chapman. 2017. Consumer perceptions of the safety of readyto-eat foods in food retail settings. J. Food Prot. 80:1364-1377

21. Luchansky, J. B., A. C. S. Porto-Fett, B. A. Shoyer, J. Phillips, V. Chen, J. Kause, D. R. Eblen, V. L. Cook, T. B. Mohr, E. Esteban, and N. Bauer. 2013. Fate of Shiga toxin-producing O157:H7 and non-O157:H7 Escherichia coli cells within refrigerated, frozen, or frozen then thawed ground beef patties cooked on commercial open-flame gas or clam-shell electric grills. J. Food Prot. 76:1500-1513.

22. Mathusa, E., Y. Chen, E. Enache, and L. Hontz. 2010. Non-O157 Shiga toxin-producing Escherichia coli in foods. J. Food Prot. 73:1721-1736.

23. Merriam, S. B., and E. J. Tisdell. 2016. Qualitative research: a guide to design and implementation (4th ed.). Jossey-Bass, San Francisco, CA.

24. Moxley, R. A. 2019. Progress in STEC control: the USDA-NIFA STEC Coordinated Agricultural Project. Food Safety Mag. 25:28-32.
25. Ortlipp, M. 2009. Keeping and using reflective journals in the qualitative research process. Qualit. Rep. 13:695-705.

26. Osaili, T., C. L. Griffis, E. M. Martin, B. L. Beard, A. Keener, and J. A. Marcy. 2006. Thermal inactivation studies of Escherichia col O157:H7, Salmonella, and Listeria monocytogenes in ready-to-eat chicken-fried beef patties. J. Food Prot. 69:1080-1086.

27. Rhee, M-S., S-Y. Lee, V. N. Hillers, S. M. McCurdy, and D-H. Kang. 2003. Evaluation of consumer-style cooking methods for reduction of Escherichia coli O157:H7 in ground beef. J. Food Prot. 66:1030-1034.

28. Rhoades, J. R., G. Duffy, and K. Koutsoumanis. 2009. Prevalence and concentration of verocytotoxigenic Escherichia coli, Salmonella enterica and Listeria monocytogenes in the beef production chain: a review. Food Microbiol. 26:357-376.

29. Ryan, T. P. 2013. Sample size determination and power. John Wiley \& Sons, Hoboken, NJ. doi.org/10.1002/978111843924.

30. Salkind, N. J. 2010. Pretest posttest design. In Encyclopedia of research design. Sage Publications, Thousand Oaks, CA. doi: 10.4135/9781412961288.

31. Samadpour, M., M. Kubler, F. C. Buck, G. A. Depavia, E. Mazengia, J. Stewart, P. Yang, and D. Alfi. 2002. Prevalence of Shiga toxin-producing Escherichia coli in ground beef and cattle feces from King County, Washington. J. Food Prot. 65:1322-1325.

32. Scallan, E., R. M. Hoekstra, F. J. Angulo, R. V. Tauxe, M.-A. Widdowson, S. L. Roy, J. L. Jones, and P. M. Griffin. 2011. Foodborne illness acquired in the United States - major pathogens. Emerg. Infect. Dis. 17:7-15.

33. Sperandio, V., and C. J. Hovde. 2015. Enterohemorrhagic Escherichia coli and other Shiga toxin-producing E. coli. ASM Press, Washington, D.C.
34. Steber, C. 2018. Phone surveys: data collection advantages and disadvantages. In communications for research. Available at: https:// www.cfrinc.net/cfrblog/phone-surveys-data-collection. Accessed on 07 August 2019.

35. Strauss, A., and J. Corbin. 1998. Basics of qualitative research: techniques and procedures for developing grounded theory. Sage Publications, Thousand Oaks, CA.

36. Thomas, M. K., R. Murray, L. Flockhart, K. Pintar, A. Fazil, A. Nesbitt, B. Marshall, J. Tataryn, and F. Pollari. 2015. Estimates of foodborne illness-related hospitalizations and deaths in Canada for 30 specified pathogens and unspecified agents. Foodborne Pathog. Dis. 12:820-827.

37. U.S. Department of Agriculture, Food Safety and Inspection Service. 2011. USDA takes new steps to fight $E$. coli, protect the food supply. Designation extends zero tolerance policy for E. coli O157:H7 to six additional $E$. coli serogroups. Available at: http://www.usda. gov/wps/portal/usda/usdahome?contentidonly=true $\&$ contentid=2011/09/0400.xml. Accessed 01 August 2019.

38. U.S. Department of Agriculture, Food Safety and Inspection Service. 2015. Safe minimum internal temperature chart. Available at: https://www.fsis.usda.gov/wps/portal/fsis/ topics/ food-safety-education/get-answers/ food-safety-fact-sheets/safe-food-handling/ safe-minimum-internal-temperature-chart/ ct_index. Accessed on 07 August 2019.

39. Wang, X., M. Taylor, L. Hoang, J. Ekkert, C. Nowakowski, J. Stone, G. Tone, S. Trerise, A. Paccagnella, T. Wong, and E. Galanis. 2013. Comparison of clinical and epidemiological features of shiga toxin-producing Escherichia coli $\mathrm{O} 157$ and non-O157 infections in British Columbia, 2009 to 2011. Can. J. Infect. Dis. Med. Microbiol. 24:e102-e106. 